\section{Condição feminina de mulheres chefes de família em situação de vulnerabilidade social}

\section{Feminine condition of women heads of family in situation of social vulnerability}

\section{Rosa Maria Ferreiro Pinto* \\ Fátima Aparecida Barbosa de Oliveira Micheletti*t Luzana Mackevicius Bernardes ${ }^{* * *}$ Joice Maria Pacheco Antonio Fernandes $s^{* * * *}$ Gisela Vasconcellos Monteiro ${ }^{*+*+*+*}$ Magda Lucia Novaes Silva ${ }^{*+t+* t}$}

* Assistente social, doutora em Serviço Social, mestrado em Saúde Coletiva, Universidade Católica de Santos — Santos/SP, Brasil. E-mail: rmferreiro@uol. com.br.

** Assistente social, mestre em Serviço Social, curso de Serviço Social, Universidade Católica de Santos Santos/SP, Brasil.E-mail: michelet@unisantos.br.

*** Enfermeira, mestre em Saúde Coletiva, curso de Enfermagem, Universidade Católica de Santos - Santos/ SP, Brasil.E-mail: luzana.bernardes@terra.com.br.

**** Enfermeira, mestre em Saúde Coletiva, curso de Enfermagem, Universidade Católica de Santos Santos/SP, Brasil. E-mail: joice@unisantos.br.

***** Psicóloga, doutora em Psicologia Social, curso de Psicologia, Universidade Católica de Santos — Santos/SP, Brasil. E-mail: gisela@iron.com.br.

****** Assistente social, mestranda em Saúde Coletiva, Universidade Católica de Santos - Santos/SP, Brasil.E-mail: magdaln@ibest.com.br
Tânia Maria Horneaux de Mendonça Barreira ${ }^{* \star * * * * *}$

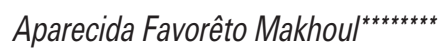
Amélia Cohn $n^{* * * * * * * *}$

Resumo: O estudo efetuou uma aproximação com a história de mulheres residentes na região central de Santos para compreender sua condição de vida, estratégias de sobrevivência e representações sobre o papel feminino e a construção de sua identidade como mulher. Utilizou-se da história oral para captar os elementos mais significativos da trajetória vivida por nove mulheres por meio de entrevistas realizadas no domicílio. A história delas mostrou processos de rupturas e continuidades, a fragilidade da população sob o efeito dos processos de vulnerabilidade e exclusão, revelando a condição feminina de mulheres em situação de vulnerabilidade social.

Palavras-chave: Condição feminina. Mulheres chefes de família. Vulnerabilidade social.

Abstract: The study approached the history of women who live in the central region of Santos to understand their life condition, their strategies to survive and their representations of the female role and of the construction of their identity as women. Nine women were interviewed in the places where they lived to get the most significant elements of their trajectory through their oral histories. Such

******* Psicóloga, mestre em Saúde Coletiva, curso de Psicologia, Universidade Católica de Santos — Santos/SP, Brasil.E-mail: obarreira@uol.com.br.

******** Psicóloga, mestre em Saúde Coletiva, mestrado em Saúde Coletiva, Universidade Católica de Santos —Santos/SP, Brasil.E-mail: aparecidafavoreto@ terra.com.br.

********* Socióloga, doutora em Sociologia, mestrado em Saúde Coletiva, Universidade Católica de Santos — Santos/SP, Brasil.E-mail: amelcohn@uol. com.br. 
histories showed processes of ruptures and continuities, as well as the fragility of the population under the effect of vulnerability and exclusion processes, and they disclosed the female condition of women in situation of social vulnerability.

Keywords: Female condition. Family-head women. Social vulnerability.

\section{Introdução}

O Nepec - Núcleo de Estudos e Pesquisas em Educação em Saúde Coletiva, ${ }^{1}$ vinculado ao Programa de Mestrado em Saúde Coletiva da Universidade Católica de Santos vem, desde 2003, desenvolvendo pesquisas na área central da cidade de Santos.

Em Santos, a população de baixa renda tem se instalado, historicamente, nas favelas da periferia, nos mangues e diques, nos porões insalubres localizados no centro da cidade e em cortiços. Segundo dados da Fundação Seade (2000), na região metropolitana da Baixada Santista 218.981 pessoas vivem em situação de extrema pobreza, o que as expõe aos mais variados riscos sociais. Especialmente na cidade de Santos, segundo a mesma fonte, 31.389 pessoas são classificadas como vivendo em situação de "vulnerabilidade alta", enquanto 21.378 atingem o mais alto grau de vulnerabilidade.

1. O Nepec é constituído por professores e alunos do Mestrado em Saúde Coletiva e de professores e alunos em Iniciação Científica dos cursos de graduação em Enfermagem, Psicologia e Serviço Social da Universidade Católica de Santos.
A situação de vulnerabilidade ${ }^{2}$ das famílias está relacionada à sua situação de pobreza, exploração e abuso, aspectos psicossociais e culturais. Porém a pobreza se expressa de muitas formas e expõe indivíduos a condições de vida muitas vezes a níveis abaixo da dignidade humana, interferindo na complexa dinâmica da vida familiar. Segundo Koga (2003, p. 19), a pobreza não se configura apenas pela ausência de renda, mas também por discriminações e sofrimentos que se superpõem, causando, consequentemente repercussões nas condições de vida.

Neste cenário têm-se verificado o aumento de famílias monoparentais, em especial aquelas onde a mulher assume a chefia do domicílio. De fato, notadamente no que se refere à estrutura da família, as unidades domésticas nesse segmento social apresentaram um crescimento significativo. No documento Síntese dos indicadores sociais (IBGE, 2009, p. 95), os dados

2. Vulnerabilidade social de pessoas, famílias ou comunidades "entendida como uma combinação de fatores que possam produzir uma deterioração de seu nível de bem-estar, em consequência de sua exposição a determinados tipos de riscos. Neste sentido, vulnerabilidade é uma noção multidimensional, na medida em que afeta indivíduos, grupos e comunidades em planos distintos de seu bem-estar, de diferentes formas e intensidades. [...] Assim, a vulnerabilidade à pobreza não se limita em considerar a privação de renda, central nas medidas baseadas em linhas de pobreza, mas também a composição familiar, as condições de acesso e a qualidade do sistema educacional, a possibilidade de obter trabalho com qualidade e remuneração adequada, a existência de garantias legais e políticas, etc." (Fundação Seade. Disponível em: <http://www.seade.gov.br>. Acesso em: 30 set. 2009. 
sobre a distribuição por sexo da pessoa de referência entre 1998 e 2008 mostra que houve um significativo aumento de mulheres nessa condição: de $25,9 \%$ para $34,9 \%$.

Conforme dados do IBGE (Censo 2000), no estado de São Paulo, 24,1 \% das famílias têm a mulher como responsável e, destas, os maiores percentuais em relação à idade das responsáveis pelos domicílios estão na faixa 35 a 54 anos, em um total de $43,7 \%$. Os domicílios com responsáveis do sexo feminino podem ser considerados um fenômeno tipicamente urbano, visto que $91,4 \%$ dos mesmos estão localizados em cidades (IBGE, 2002, p. 12-37).

Nas camadas mais pobres da população, as famílias chefiadas por mulheres, de acordo com Carvalho (1998, p. 85), são em grande parte associadas às situações de vulnerabilidade econômica, pois a mulher, como único membro adulto do domicílio, é sua provedora, além de assumir funções domésticas e o cuidado com os filhos, o que implica sua vinculação em trabalhos mal remunerados em tempo parcial ou intermitente, gerando assim maiores dificuldades para garantir a subsistência da própria família.

Por outro lado, famílias chefiadas por mulheres são em grande parte decorrentes de uma gravidez precoce ou indesejada, instabilidade familiar e abandono. Não raro essas mulheres foram ou ainda são vítimas de violência doméstica em suas mais variadas vertentes, incluindo-se a "invisível", aquela que não deixa marcas exteriores, mas sequelas profundas em relação à sua autoestima e à busca ou re- construção de sua identidade como mulher, como cidadã e aos preconceitos decorrentes da relação de gênero. Esse universo foi captado pelos pesquisadores do Nepec em pesquisa realizada em cortiços na cidade de Santos, onde as mulheres tiveram um destaque especial, notadamente as que chefiam suas famílias ${ }^{3}$.

A sobrecarga de papéis assumidos pelas mulheres frente às dificuldades sociais, econômicas e de violência experimentadas por elas expôs uma face perversa da condição feminina, sobressaindo, por um lado, a baixa autoestima, as frustrações, os medos e anseios e, por outro, a coragem e a perseverança na luta pela sobrevivência.

A par da vulnerabilidade social a que estão expostas, pode-se constatar que elas também apresentam alto grau de vulnerabilidade emocional, seja pelo sentimento de abandono, seja pela violência e exploração a que foram submetidas, seja pela fragilização a que estão expostas cotidianamente na busca de estratégias para a sobrevivência de seu núcleo familiar.

Para aprofundar o conhecimento sobre as histórias de vida, as dificuldades enfrentadas pelas mulheres que cuidam sozinhas de suas famílias, a percepção que têm sobre sua condição feminina, como se utilizam de redes de apoio e de serviços, suas representações sobre sexualidade, maternagem e estratégias de sobrevivên-

3. O Nepec desenvolveu a pesquisa "Cortiços na cidade de Santos: avaliação das condições de vida e saúde em microespaço urbano" finalizada em fevereiro de 2008. Auxílio financeiro do CNPq (Processo n. 400575/2006-0). 
cia, o Nepec desenvolveu a pesquisa intitulada "Mulheres chefes de família em situação de vulnerabilidade social residentes no centro de Santos: emoções, estratégias de sobrevivência e repercussões na sua saúde e da família", ${ }^{4}$ da qual este artigo é um recorte.

O estudo da condição feminina, da família e seus arranjos e de sua vida cotidiana tornaram-se importantes eixos referenciais para a compreensão e a explicação da vida dos sujeitos na construção de seus modos de vida, na sociedade capitalista. Esses eixos referenciais tiveram como substrato a perspectiva marxista que inspirou a construção das categorias centrais que regeram a metodologia e a análise aqui presentes.

Neste estudo, a família pressupôs o espaço para a garantia da sobrevivência do desenvolvimento e da proteção integral dos filhos e demais membros, independentemente do arranjo familiar ou da forma como vêm se estruturando. Ou seja, a família se constitui em um lugar das potencialidades protetoras, devendo ser compreendida como grupo social cujos movimentos de organização/reorganização mantêm estreita relação com o contexto sociocultural (Ferrari e Kaloustian, 2000, p. 11-12). O estudo do tema tornou-se fundamental para a compreensão da trajetória das mulheres e de suas famílias, pois também pode desvelar a condição feminina nas classes subalternas.

4. Auxílio financeiro da Fapesp (Processo n. 06/ 58893-7).
Por outro lado, a relação entre chefia feminina e pobreza evidencia a situação generalizada da mulher ocupando os piores postos de trabalho, obtendo a menor remuneração e a sua vinculação a atividades informais, portanto mais sujeita às oscilações do mercado de trabalho do setor informal. Ao mesmo tempo, na sociedade brasileira, é a mulher quem assume as funções domésticas e o cuidado com os filhos, além da pressuposta subordinação ao namorado ou companheiro. Nesse sentido, é importante compreender as representações que estão inseridas nas relações familiares, na violência doméstica e suas vertentes, inclusive a psicológica, e o impacto que isso provoca nesses sujeitos que são, concomitantemente, mulheres trabalhadoras e chefes de família.

Para se compreender as relações que envolvem a dinâmica da vida familiar da mulher chefe de família e penetrar na sua complexidade, o estudo da cotidianidade tornou-se importante, pois o cotidiano é espaço único e possível de o indivíduo viver sua vida e realizar sua humanidade. É na vida cotidiana que o indivíduo busca sua existência e subsistência na sociedade, por meio de sua prática social.

O mundo cotidiano é a realidade subjetiva, mas objetivada pelos processos de significação construídos a partir do intersubjetivo do senso comum. É, pois na estrutura da vida cotidiana da mulher e sua família, com suas limitações e possibilidades, que foi possível compreender como o grupo familiar se movimenta e como constrói sua trajetória de vida e as estratégias 
necessárias à sua manutenção como ser individual e coletivo.

Um olhar sobre a família, e especialmente sobre a mulher chefe de família, supõe reconhecer que as condições adversas de vida podem impactar as relações familiares e sociais. Assim, duas categorias de análise, tomadas a priori, tornaram-se fundamentais para este estudo: empoderamento e estratégias de sobrevivência, porque estão intimamente vinculadas e favorecem o empoderamento e em alguns casos a resiliência, observados na trajetória de vida das mulheres. Processo de $r e-$ siliência aqui entendido como

um sistema em si mesmo, envolvendo um processo dinâmico de interação entre vários aspectos tais como os fatores de risco e protetores (individuais, familiares e comunitários), o contexto histórico e o social, mediados pela interpretação e pela atribuição de significados. (Souza, 2004, p. 81)

A vulnerabilidade à pobreza a que estão expostas as mulheres pesquisadas não se limita a considerar apenas a privação de renda, mas também a dinâmica da vida familiar, o acesso a serviços públicos, a possibilidade de obter trabalho com qualidade e remuneração adequadas, a existência de garantias legais e políticas.

As estratégias de sobrevivência se colocam desta forma na construção do projeto de vida desses sujeitos, no sentido de buscarem o que querem e o que podem construir a partir dos recursos de que dispõem, ou seja, da sua capacidade para enfrentar as dificuldades imediatas e me- diatas para sua reprodução social. Estratégias supõem também a capacidade de se reestruturar diante das vicissitudes da vida e fortalecer sua identidade e, assim, criar condições próprias para sobreviver.

\section{Metodologia}

Para debruçar-se nesse instigante universo feminino o estudo teve como objetivos:

- conhecer a história e a dinâmica de famílias chefiadas por mulheres do centro de Santos;

- avaliar as condições de vida e de vulnerabilidade social em que se encontram as mulheres chefes de família;

- conhecer suas estratégias de sobrevivência para manutenção das famílias e os impactos na sua saúde e na do grupo familiar.

Os procedimentos metodológicos para a captura do objeto investigado foram inerentes a uma proposta teórico-metodológica a partir da qual se destacam as relações entre o indivíduo e a sociedade, sujeito e objeto, aspirações, crenças e valores, estrutura e significados, tomados na totalidade do processo histórico da sociedade, que é determinante do conjunto das relações sociais que por ele perpassam. Conhecer o modo de vida dos sujeitos pressupõe o conhecimento de sua experiência social, e para isso é necessário ouvi-los e permitir-lhes que se revelem no contexto em que vivem. 
A pesquisa qualitativa, ${ }^{5}$ além de ser uma opção dos pesquisadores, justificou-se pela complexidade do objeto e suas particularidades. Pela natureza do estudo, a história de vida foi a metodologia escolhida. Por meio dela foi possível apreender as experiências subjetivas e objetivas dos sujeitos, de seu grupo social e os significados que atribuem aos seus modos de vida.

Conforme referem Gonçalves e Lisboa (2007), os relatos orais foram pouco a pouco sendo valorizados pelas ciências sociais, na medida em que por intermédio deles se percebe que comportamentos, valores e emoções permanecem escondidos nos dados estatísticos.

O método da história oral, em suas vertentes histórias de vida, narrativas, trajetórias de vida, requer o uso de fundamentos epistemológicos, isto é, o pesquisador deve orientar-se através de pressupostos que delimitam o entendimento sobre o uso dos procedimentos metodológicos em questão, que por sua vez definirão o caráter de investigação social. (Gonçalves e Lisboa, 2007, p. 86)

O método da história oral, segundo as autoras, utiliza diferentes técnicas de en-

5. De acordo com Minayo, pesquisa é atividade básica das ciências na indagação e descoberta da realidade. Segundo a autora: "é uma atitude e uma prática teórica de constante busca que define um processo intrinsecamente inacabado e permanente. É uma atividade de aproximação sucessiva da realidade que nunca se esgota, fazendo combinação particular entre teoria e dados" (2000, p. 23). trevistas para dar voz aos sujeitos invisíveis e, por meio da singularidade de seus depoimentos, construir e preservar a memória coletiva (Gonçalves e Lisboa, 2007, p. 87).

Colher as histórias de vida de mulheres chefes de família em situação de vulnerabilidade social favoreceu a compreensão não só da condição feminina nesse segmento da população, com características marcantes e singulares, como também dos processos sociais vividos por esse grupo de sujeitos, trazendo à luz elementos ainda pouco conhecidos, ou melhor reconhecidos, das situações específicas de mulheres chefes de família nesse contexto.

$\mathrm{O}$ universo da pesquisa foi a região central da cidade de Santos, composta pelos bairros: Centro, Paquetá, Vila Mathias e Valongo. A escolha dos sujeitos deu-se a partir dos seguinte critérios: a) mulheres que vivem sozinhas com suas famílias ou agregados em situação de vulnerabilidade social; b) mulheres que residem nos bairros do centro da cidade de Santos. Nove mulheres participaram do estudo.

A metodologia utilizada exigiu um delicado processo de abordagem e o estabelecimento de vínculos dos pesquisadores com as mulheres para que as narrativas ocorressem de forma satisfatória. Tal procedimento exigiu tempo e cuidado para que os sujeitos pudessem contar livremente suas histórias de vida em clima de confiança e se mantivessem disponíveis para isso. A pesquisa de campo só pôde 
ocorrer a partir da disponibilidade de tempo dos sujeitos e do clima do domicílio, ou do local de moradia, pois os sujeitos residiam em cortiços ou casas subdivididas, tipo de moradia comum no centro da cidade de Santos.

A entrevista não estruturada foi o instrumento pelo qual se corporificaram as narrativas. As entrevistas, em sua maioria, ocorreram no domicílio dos sujeitos, e o número de entrevistas por sujeito variou (em média foram quatro) de acordo com a necessidade do estudo. Como as entrevistas foram realizadas no domicílio, ocorreram várias interrupções e intercorrências próprias da vida cotidiana dos sujeitos. Esse aspecto, se por um lado favoreceu a apreensão da dinâmica da vida familiar, por outro fez com que o procedimento de coleta de dados fosse lento. Embora tenha sido elaborado um roteiro prévio, a coleta das narrativas respeitou o ritmo dos sujeitos.

O projeto foi submetido ao Comitê de Ética da Universidade Católica de Santos, Processo Copop n. 319/16 e aprovado em 22/5/2007.

As entrevistas foram gravadas e transcritas mediante a assinatura do Tecle Termo de Consentimento Livre e Esclarecido. A observação foi outro recurso utilizado para apreensão do universo familiar e de suas relações, por meio de anotações no diário de campo. A coleta das narrativas foi realizada em duplas de pesquisadores, sendo um deles referência em função do vínculo estabelecido com o sujeito.

\section{Resultados e discussão}

A faixa etária das nove mulheres sujeitos da pesquisa variou de 28 a 53 anos, sendo que três tinham entre 28 e 33 anos, quatro mulheres entre 38 a 45 anos, e duas encontravam-se na faixa de 50 a 53 anos. Em relação ao estado civil, duas já foram casadas e estavam separadas, e as demais sete eram solteiras.

Quatro das mulheres haviam estudado até a $4^{\mathrm{a}}$ série do Ensino Fundamental, uma até a $5^{\text {a }}$ série, uma havia completado o Ensino Fundamental, uma era analfabeta, uma estava cursando, com bolsa de funcionária (inspetora de alunos em uma universidade da região), o primeiro ano de um curso superior. Uma delas não quis informar a escolaridade.

Em relação à composição familiar, cinco mulheres viviam sozinhas com seus filhos, três com filhos e netos, e uma delas, com dois filhos adultos e com uma irmã. A média de pessoas sob a responsabilidade das mulheres era de cinco indivíduos. A idade das crianças - filhos e netos variou de um a dezessete anos.

No que se refere à religião, três se declararam católicas (embora dessas, duas disseram-se também evangélicas e uma declarou ser espírita), duas declararam que creem em Deus, duas eram evangélicas, uma era budista e uma afirmou não ter nenhuma religião. Nesse aspecto, nota-se que as crenças não são bem definidas que as religiões se mesclam.

Das nove mulheres entrevistadas, apenas duas possuíam trabalho com registro 
em carteira, sendo que uma com contrato temporário; as demais sobreviviam do trabalho informal. Algumas faziam artesanato com o apoio da Associação dos Moradores dos Cortiços e vendiam sua produção nas redondezas. As profissões e atividades relatadas pelas mulheres foram: sucateira, cozinheira, balconista, inspetora de alunos, empregada doméstica, ambulante, faxineira, copeira, manicure, servente de pedreiro, artesanato e reciclagem de materiais.

A necessidade de cuidar dos filhos foi relatada como um empecilho para se obter trabalhos mais bem remunerados e registrados em carteira, obrigando as mulheres a optarem por serviços com horários mais flexíveis.

A renda mensal variou de um a dois salários mínimos. Duas eram beneficiárias do Programa Bolsa Família e as demais buscavam auxílio e cestas básicas em Organizações Não Governamentais da região. A alimentação foi o item que se destacou como aquele que mais sobrecarregava o orçamento doméstico. As crianças estudavam na rede pública municipal e recebiam o material escolar e os uniformes da Secretaria de Educação da Prefeitura Municipal de Santos.

Das nove mulheres, cinco eram naturais do estado de São Paulo e quatro eram migrantes de estados do Nordeste, o que de certa forma contesta o argumento fundamentalista de que a causa da existência de um volume significativo de pobres na região deve-se quase que exclusivamente à vinda da população nordestina para cá.

As expressivas desigualdades econômicas e sociais são visíveis na cidade de
Santos: a população mais abastada reside nas áreas mais próximas da orla da praia, enquanto bolsões de pobreza são encontrados na região do centro, próximo à área portuária. Nestes, evidenciam-se baixo nível de escolaridade, famílias com elevado número de filhos, chefia feminina da família, moradias insalubres e em local perigoso, alimentação insuficiente e/ou inadequada, doenças na família, subempregos e a dupla ou tripla jornada de trabalho das mulheres são fatores que as impelem a não usufruir de seus direitos nem como mulheres, nem como cidadãs.

Os dados da pesquisa foram analisados a partir de três grandes eixos referenciais: a condição feminina de mulheres chefes de família, trajetória de vida e resiliência e estratégias de sobrevivência e vulnerabilidade social. Para este artigo foi destacada apenas a condição feminina, a qual pode ser avaliada a partir dos seguintes pontos: direitos sexuais e direitos reprodutivos; relações de gênero e violência; representações sobre feminilidade e construção da identidade. E uma primeira evidência que se destaca dos dados levantados é que a vulnerabilidade social a que estão submetidas essas mulheres é fator preponderante para a manutenção da subordinação feminina.

\section{Direitos Sexuais e Direitos Reprodutivos}

Do ponto de vista dos direitos sexuais e reprodutivos foram levantadas, por meio das entrevistas, questões relacionadas à 
vida sexual das mulheres, como saúde, gravidez, parto, planejamento familiar, sexo seguro e acesso às políticas e aos serviços públicos de saúde.

Os métodos anticoncepcionais hormonais foram descritos como ineficazes e difíceis de utilizar, inclusive a pílula do dia seguinte, seja pela não compreensão adequada da sua administração, seja pelo acúmulo de tarefas que as fazem esquecer a medicação, ou ainda pelos seus efeitos colaterais desagradáveis.

O uso da "camisinha" foi referido apenas por uma das entrevistadas que não utilizava outro método anticoncepcional; as demais aceitavam ter relação sexual sem "camisinha". Segundo os relatos, os parceiros se recusavam a utilizar a "camisinha", e elas não apresentavam resistência frente a essa negativa, demonstrando, desta forma, a submissão cultural feminina na esfera sexual.

$\mathrm{O}$ discurso das mulheres em torno da "camisinha" mostrou que esta não é percebida com o caráter de proteção contra DSTs. Quando citada, foi somente no sentido de evitar a gravidez. A gravidez indesejada foi citada por todas as mulheres. As reações frente a essa situação foram de depressão, tristeza e raiva do parceiro.

Em relação ao planejamento familiar, o governo federal lançou, em 2006, um programa que conta com uma série de cartilhas que oferecem informações sobre direitos sexuais, direitos reprodutivos e métodos anticoncepcionais e com ações educativas individuais ou em grupo sobre o mesmo tema. Entretanto, nenhuma dessas mulheres teve acesso a essas informações.
As questões em relação aos direitos sexuais e reprodutivos das mulheres pressupõem o direito de escolher quando, onde e com quem ter relações sexuais, sem sofrer coerção ou qualquer tipo de violência, o que não ocorreu com as pesquisadas. Estas questões evidenciam as relações de gênero e violência a que foram submetidas.

\section{Relações de gênero e violência}

A relação de gênero não é somente entre diferentes: ela é sinônima de uma relação onde imperam a desigualdade e a injustiça.

A subordinação da mulher e a violência de gênero na sociedade brasileira estão presentes em todos os extratos sociais, notadamente entre as mulheres em situação de vulnerabilidade social. Os direitos da mulher são cotidianamente desrespeitados, gerando expressões de uma mesma face, a violência, seja ela de gênero, intrafamiliar, doméstica, física, psicológica, econômica e financeira, sexual ou institucional.

Nos relatos das mulheres foi identificada a violência sexual na infância em várias ocasiões e foi possível perceber por ocasião dos depoimentos que eram situações extremamente dolorosas e que ainda estavam muito vívidas na lembrança delas. $\mathrm{Na}$ infância e adolescência, a violência intrafamiliar esteve presente em várias histórias. Uma delas foi estuprada pela primeira vez aos três anos de idade, o que se repetiu em outras ocasiões ainda na infância. 
A violência de gênero geralmente é praticada pelos companheiros, mas também por ex-companheiros. A agressão física de gênero foi relatada de forma importante por duas das entrevistadas; outras relataram agressões verbais e psicológicas. A coerção sexual marital realizada por meio de violência física ou psicológica foi referida pelos sujeitos, demonstrando a força cultural legitimando o que não é natural e reforçando a condição de subordinação das entrevistadas.

A utilização de drogas lícitas e ilícitas esteve presente em todas as histórias, seja pelos pais, pelos companheiros, bem como pelas próprias entrevistadas. Entre as mulheres, três relataram o uso de maconha, cocaína e álcool no passado, principalmente quando estavam com companheiros que eram usuários, e duas delas também traficavam por imposição dos mesmos, salientando uma vez mais a subordinação feminina.

A vida dessas mulheres revelou que a condição feminina de mulheres chefes de família em situação de vulnerabilidade social está permeada por toda forma de violência. Mas é também a partir dessa exposição à violência e do seu enfrentamento que elas constroem suas identidades como mulheres, mães e avós.

\section{Representações Sobre a Feminilidade e a Construção da Identidade}

Duveen (2003) refere que a criança nasce em um mundo já estruturado pelas representações sociais de sua comunidade, garantindo a ela a tomada de um lugar em um conjunto sistemático de relações e práticas sociais. Segundo o autor, em relação ao desenvolvimento dos gêneros, esta perspectiva é importante porque se trata de uma dimensão poderosa e onipresente do mundo social.

Representações de gênero fornecem uma referência importante através da qual a criança adquire uma identidade que lhe permite situar-se no mundo social. [...] Sejam quais forem as representações internalizadas, elas estão entrelaçadas aos processos de construção de identidade, ainda que as consequências da identidade nem sempre sejam as mesmas. (Duveen, 2003, p. 266)

As representações de gênero são importantes neste aspecto porque geralmente se referem a uma dimensão de poder social. Da mesma forma que representa diferença, a imagem dos gêneros como oposições bipolares também representa hierarquia, já que a relação entre gêneros é, historicamente, de poder e traz consequências para as definições do "eu". Segundo Duveen (2003), pensamos em nós mesmos como homens ou mulheres, e isto significa que essas identidades sociais emergem à medida que internalizamos representações de gênero.

As representações estão sempre em construção e constituem o mundo tal como ele é conhecido. Portanto as identidades que elas sustentam garantem aos indivíduos um lugar neste mundo. A construção 
de uma identidade é um modo de organizar significados para que os indivíduos se posicionem como atores sociais, contribuindo para a definição do eu. A identidade é formada por processos sociais e deriva da dialética entre indivíduo e sociedade.

Considerando esses aspectos, a pesquisa revelou que dos membros das famílias das mulheres entrevistadas, a figura materna apareceu como sendo de destaque na maioria das histórias de vida, relacionada de alguma forma a sentimentos negativos, seja pela violência física, psicológica ou pela própria ausência.

A figura materna também representou a reprodução dos valores machistas e da subordinação feminina, pois na maioria das histórias elas próprias se submetiam a seus companheiros e, apesar dos maustratos, se resignavam e ainda ensinavam às filhas que o casamento era a melhor opção de vida para as mulheres.

A figura paterna, de um modo geral, foi retratada como ausente ou negativa. A visão que essas mulheres possuíam sobre a paternidade está embasada em suas histórias de vida, em vivências constituídas nas relações estabelecidas e acumuladas ao longo da sua história, em um contexto social, histórico e cultural. A distinção dos papéis de pai e mãe foi observada através de construções sociais de gênero elaboradas a partir das diferenças atribuídas às diferenças sexuais. As construções de gênero, baseadas no modelo patriarcal, ficaram evidentes, relacionando a maternidade à sensibilidade e à submissão, e a paternidade à força.
No entanto, a capacidade de criar os filhos e de ter controle sobre o dinheiro, relacionadas com a atribuição de dona de casa e chefe de família, reforça a força feminina. O espaço doméstico apresenta-se no imaginário dessas mulheres ainda como um território predominantemente feminino. As mulheres assumem posição ativa na esfera da família. Ao tomarem para si o comando de suas famílias enquanto "chefes", tendem a quebrar a divisão de "papéis" onde o homem é o provedor, e a mulher, dependente e submissa.

Cumprir o papel masculino de provedor não configurou um problema para as entrevistadas. Embora o fardo seja pesado, todas estavam acostumadas a trabalhar desde muito cedo. $\mathrm{O}$ trabalho adquire um sentido de afirmação de si enquanto mulher e enquanto provedora de seus lares. Nesse aspecto, a relação trabalho e cuidado com a família fortalecem a construção da identidade feminina, um jeito especial de ser mulher. Para as mulheres, o trabalho significa mais do que a sobrevivência material, até porque seus parcos rendimentos mal cobrem as necessidades imediatas da família.

A múltipla jornada de trabalho resulta, geralmente, em abdicar de sua feminilidade, de cuidados com sua saúde e de sua sexualidade pelo estresse cotidiano desencadeado na luta pela sobrevivência. Referiram não ter tempo para cuidar de si. A disposição para o trabalho pode ser considerada uma força positiva que recompensa o estado de pobreza e vulnerabilidade.

O trabalho assume também uma condição de autoafirmação como mulheres 
provedoras e, assim, elas constroem sua autonomia diante do poder masculino.

As mulheres colocaram uma centralidade na relação mãe-filho, evidenciada nas narrativas das entrevistadas pelo valor atribuído por todas elas à maternidade. $\mathrm{O}$ amor materno, compartilhado por todas as mulheres, demarca a identidade feminina no espaço do lar. Para algumas delas, principalmente as mais velhas, essa capacidade transforma a mulher muito mais em mãe do que em mulher, tornando o sentimento da maternidade uma recompensa em suas vidas. De alguma forma diferenciam seus papéis femininos, legitimados socialmente, a partir da relação mãe-filhos.

Em seus sonhos e projetos de futuro a moradia tem sempre lugar de destaque. A casa própria aparece com uma representação de liberdade, de conforto e recompensa pelo trabalho. Como residem em habitações coletivas, muitas vezes em apenas um cômodo de cortiço, uma moradia mais digna representa melhorar de vida.

\section{Consideraç̃os finais}

A história dessas mulheres mostrou um processo de rupturas e continuidades. Trazem a marca da exclusão social, mas patrimônios pessoais as impelem a sobreviver em situações adversas. O enfrentamento dessas situações faz com que elas superem suas experiências negativas e encontrem forças para reconstruir suas trajetórias. O que se desvelou, nesse estudo, foram as manifestações da exclusão social na vida dessas mulheres, que já são oriundas de famílias pobres, também transfiguradas de seu papel protetor pela miséria física, psicológica e emocional.

A história delas mostrou a fragilidade da população que se situa nas franjas da estrutura social do sistema capitalista da semiperiferia que sofre o efeito dos múltiplos processos de vulnerabilidade e exclusão.

As estratégias por elas utilizadas mostram o esforço e o investimento pessoal para se reproduzirem e se representarem como mulheres do seu tempo e que fizeram seu tempo histórico forjado em uma trajetória de sofrimento para, assim, construírem suas identidades como "guerreiras", que é o termo que utilizam para se autodenominar na busca de uma vida nova.

Remetê-las às suas memórias exigiu o respeito dos pesquisadores em deixar que focassem os aspectos mais marcantes de sua trajetória de vida, mesmo que muitas vezes a ordem cronológica das narrativas fosse interrompida. Essas lembranças foram marcadas por um movimento de negação, afirmação e de construção, exigindo do pesquisador ouvinte, acuidade para captar a essência dos fatos ocorridos e sua repercussão na vida presente. Foram memórias extraídas de um cotidiano onde se evidenciaram a individualidade dos sujeitos, rumo à construção de uma identidade muitas vezes descolada do sujeito mulher e dos laços familiares de origem.

Artigo recebido em maio/2010

Aprovado em dez./2010 


\section{Referências bibliográficas}

CARVALHO, L. Família chefiada por mulheres: relevância para uma política social dirigida. Revista Serviço Social \& Sociedade, São Paulo, ano XIX, n. 57, p. 74-98, jul. 1998.

DUVEEN, G. Crianças enquanto atores sociais: as representações sociais em desenvolvimento. In: GUARESCHI, P.; JOVCHEKOVITCH, S. (Orgs.). Textos em representações sociais. Petrópolis: Vozes, 2003. p. 261-293.

FERRARI, M.; KALOUSTIAN, S. M. Introdução, p. 11-15. KALOUSTIAN, S. M. (Org.). Família Brasileira, a base de tudo. 4. ed. São Paulo: Cortez; Brasília: Unicef, 2000.

FUNDAÇÃO SISTEMA ESTADUAL DE ANÁLISE DE DADOS. Informação dos Municípios Paulistas - Região Metropolitana da Baixada Santista, 2000.

. Espaços e dimensões da pobreza nos municípios de São Paulo. Secretaria de Economia e Planejamento do Governo do Estado de São Paulo. Disponível em: $<$ http://www.seade. gov.br>. Acesso em: 30 set. 2009.

GONÇALVES, R. C.; LISBOA, T. K. Sobre o método da história oral em sua modalidade trajetórias de vida. Revista Katálysis. Florianópolis, v. 10, n. especial, p. 83-92, 2007.
INSTITUTO BRASILEIRO DE GEOGRAFIA E ESTATÍSTICA. Perfil das mulheres responsáveis pelos domicílios no Brasil 2000. Departamento de População e Indicadores Sociais. Rio de Janeiro: IBGE, 2002.

Síntese de indicadores sociais: uma análise das condições de vida da população brasileira. Diretoria de Pesquisas. Estudos e Pesquisas - Informação Demográfica e Socioeconômica, n. 26. Rio de Janeiro: IBGE, 2009.

KAlOUSTIAN, S. M. (Org.). Família brasileira: a base de tudo. São Paulo: Cortez; Brasília: Unicef, 2004.

KOGA, D. Medida de cidades: entre territórios de vida e territórios vividos. São Paulo: Cortez, 2003.

MINAYO, M. C. S. O desafio do conhecimento: pesquisa qualitativa em saúde. São Paulo: Hucitec; Rio de Janeiro: Abrasco, 2000.

PINTO, R. M. F. Mulheres em situação de vulnerabilidade social residentes na região central da cidade de Santos: emoções, estratégias de sobrevivência e repercussões na sua saúde e da família. CNPq/Relatório Técnico-Científico de Projeto Individual de Pesquisa. Santos: 2008. p. 114, Mimeo.

SOUZA, M. T. S. Família e resiliência. In: CERVENY, C. M. O. (Org.). Família e... São Paulo: Casa do Psicólogo, 2004. p. 53-84. 